\title{
Virology in a "post-truth" world
}

We are living in a very strange time that has been dubbed a "post-truth" world. For example, Chuck Todd, the host of the NBC TV programme Meet the Press, asked Kellyanne Conway, President Trump's counsellor, to clarify the comments by White House Press Secretary Sean Spicer about the size of the audience attending the Trump inauguration ceremony. They disputed the number of attendees as revealed by aerial photographs of the current and previous inaugurations. Eventually, Todd got the interpretation(1) that Spicer had provided "alternative facts."

Such a concept is anathema for those of us with a scientific bent who accept that facts are things that are measurable, reproducible and have been validated. This does not naïvely assume that facts have absolute values, as shown by the error bars that scientific papers routinely include as a way of quantifying uncertainty around the measurements. It does mean that facts are solid entities that can be used as a basis for rational discussion. For example, facts may be subjected to alternative interpretations about their significance for society without disputing their veracity. However, the more such interpretations deviate from the median, the greater the chance that the propounder belongs to the world of politics rather than the world of science.

There is always the potential for the public record to be contaminated by statements purporting to be true which are simple errors, inadvertent falsehoods, misconceptions, or downright lies. The underlying error may be the same in each case, but the description used will depend upon the intention of the original author; did they make an honest mistake, fall into an understandable misinterpretation or deliberately set out to mislead? The Internet allows us to be directed to websites presenting the case for an amazing variety of subjects. The veracity of the information displayed on a particular unique resource locator (URL) does not correlate with the slickness of the presentation, so there are no apparent warnings that one may be about to enter a "post-truth" area or one containing "alternative facts." The algorithms that drive searches for information are based on the number of earlier searches for the same keywords that have linked to the same URL; a measure of popularity that cannot validate a particular website in terms of factual accuracy appropriate for identifying scientific facts.

The same applies to the use of citations to particular articles in the primary scientific literature, as can be illustrated simply. Search for "side-effects of MMR vaccine" and you will come across a 1998 publication in the renowned Lancet by Wakefield et al that will have been credited with many citations before it was formally retracted.(2) This apparent popularity belies the fact that virtually all of the citations represent authors explaining why the information in the original article is incorrect, false and/or misleading.(3) To try to prevent such calamities we have checks and balances in scientific publishing, in the form of peer review and editorial review, to reduce the possibility that authors may mislead themselves into wishful thinking. This is an application of the basic tenet of training and examining students to PhD level as encapsulated 
in the request: "show me how your interpretations are supported by your data and how you have considered and excluded alternative explanations".

The principles that govern the publication of primary research data apply equally to review articles, such as the ones published here. Readers want to be updated on developments outside their own research area, but cannot be expected to have personal experience of the specialised techniques used in every part of Virology. While readers may not comprehend every detail of the research techniques used, they will make the effort to understand the implications of the research. This means that the conclusions reached by the authors of the review article, and the perspective given on the direction of travel for the subject, must be anchored in secure facts. If your search brings you to the website of Reviews in Medical Virology, you can be assured that the authors, peer reviewers and editors have done their best to ensure that the factual information you encounter is accurate and not misleading. We state explicitly in our instructions that: "we encourage authors to speculate on the implications of their research, but the speculation should be kept separate from scientific information whose validity has been definitively proven." I doubt if Kellyanne Conway and her colleagues read our articles, but they are very welcome to take this sentiment to heart.

PD Griffiths

1. E S. Alternative Facta. Available from:

http://www.vanityfair.com/news/2017/01/kellyanne-conway-alternative-facts.

2. Wakefield AJ, Murch SH, Anthony A, Linnell J, Casson DM, Malik M, et al. Ileal-lymphoid-nodular hyperplasia, non-specific colitis, and pervasive developmental disorder in children. Lancet. 1998;351(9103):637-41.

3. MMR vaccine controversy. Available from:

https://en.wikipedia.org/wiki/MMR_vaccine_controversy. 